\title{
微图案化钙磷盐膜层的电化学构筑及其生物性能
}

\author{
黄勇虾赖跃坤林龙翔孙岗 * 林昌健 * \\ (厦门大学化学化工学院化学系, 福建 厦门 361005)
}

\begin{abstract}
摘要：基于表面分子自组装和光催化转印技术, 在 $\mathrm{TiO}_{2}$ 膜层表面获得超亲/超疏水阵列微图案模板, 结合电化 学沉积技术, 成功制备了微图案化钲磷盐膜 $(\mathrm{CaP})$ 层. 扫描电子显微镜(SEM)和电子探针分析(EPMA)结果表明, 通过超亲/超疏水阵列微图案模板可构筑高空间分辨的微图案化钻磷盐膜层. 微图案化钙磷盐膜层的体外 MG63 细胞培养证实, 细胞对钙磷盐膜层微单元有强烈的选择性粘附作用, 从而可望控制细胞在微单元中的贴壁生 长, 实现高通量评价细胞行为.
\end{abstract}

关键词： $\mathrm{TiO}_{2}$; 超亲/超疏水; 钙磷盐膜层; 微图案; 生物性能 中图分类号: 0646

\section{Electrochemical Construction and Biological Performance of Micropatterned CaP Films}

\author{
HUANG Yong-Xia LAI Yue-Kun LIN Long-Xiang SUN Lan* LIN Chang-Jian * \\ (Department of Chemistry, College of Chemistry and Chemical Engineering, Xiamen University, Xiamen 361005,
}

Fujian Province, P. R. China)

\begin{abstract}
Based on surface molecule self-assembly and photocatalytic lithography techniques, superhydrophilic/ superhydrophobic micropatterns were fabricated on $\mathrm{TiO}_{2}$ films. Micropatterned calcium phosphate $(\mathrm{CaP})$ films were successfully fabricated by the as-prepared superhydrophilic/superhydrophobic template combined with the electrochemical deposition method. Scanning electron microscopy (SEM) and electron probe microanalysis (EPMA) indicated that micropatterned $\mathrm{CaP}$ films with a high spatial resolution could be constructed using the superhydrophilic/ superhydrophobic micropatterns as templates. In vitro MG-63 cell tests of the micropatterned CaP films showed that the cells selectively adhered to the tiny $\mathrm{CaP}$ film units, which is promising for the control of the adherent growth of the cells on the tiny units and to achieve a high throughput evaluation of the cell behavior.
\end{abstract}

Key Words: Titania; Superhydrophilic/superhydrophobic; CaP film; Micropattern; Biological performance

细胞与生物材料的相互作用是一个非常重要的 研究领域 ${ }^{[1]}$, 而如何有效地引导和控制细胞在材料 表面的粘附行为是一个关键性的问题 ${ }^{[2-5]}$. 早在 1912 年, “接触引导”现象研究的先驱 Harrison ${ }^{[6}$ 通 过实验证实细胞可沿蜘蛛丝方向生长, 第一次报道
了材料拓扑结构对细胞行为的影响, 推动了蛋白质 和细胞图案化研究领域的问世. 近年来, 各种物理、 化学、生物等新的表面图案化技术不断涌现, 如软

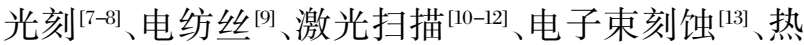
模压印技术 ${ }^{[14]}$ 等. 研究者们通过多种方法在不同材

Received: March 29, 2010; Revised: May 20, 2010; Published on Web: June 30, 2010.

*Corresponding authors. Email: sunlan@xmu.edu.cn, cjlin@xmu.edu.cn; Tel: +86-592-2184655.

The project was supported by the Major International Collaborative Research Projects of the National Natural Science Foundation of China (20620130427), National Natural Science Foundation of China (20773100), National Key Basic Research Program of China (973) (2007CB935603) and International Scientific and Technological Cooperation Projects of the Ministry of Science and Technology of China (2007DFC40440). 国家自然科学基金-重大国际合作研究项目(20620130427), 国家自然科学基金项目(20773100), 国家重点基础研究发展规划项目(973) (2007CB935603)和国家科技部国际合作重大项目(2007DFC40440)资助

C. Editorial office of Acta Physico-Chimica Sinica 
料表面制作出尺寸各异的图案, 并利用此类图案引 导和控制成纤维细胞、成骨细胞、上皮细胞、成肌细 胞等多种细胞的响应, 包括细胞的生长、发育、增殖、 分化及迁移等一系列事件 ${ }^{[15-16] . ~}$

具有浸润性差异的超亲/超疏水性膜层图案化 技术受到了人们广泛的关注. 研究发现, 如能在同一 材料表面集成大量不同润湿性的单元, 有可能获得 更加诱人的特性. 所谓超亲水表面是指与水接触角 小于 $5^{\circ}$ 的表面, 而超疏水表面是指与水的接触角大 于 $150^{\circ}$ 的表面. 从超亲水到超疏水的梯度表面集成 可赋予表面更大的取向驱动力, 驱动液体移动沉积, 这无疑是对固-液浸润性研究和应用的进一步拓展, 对科学研究和实际应用均有潜在的重要意义. 如 Tadanaga 等 ${ }^{[17}$ 利用溶胶凝胶法和水热法在玻璃片表 面制备花族状的 $\mathrm{Al}_{2} \mathrm{O}_{3}$, 提拉覆盖 $\mathrm{TiO}_{2}$ 膜层后, 结合 自组装方法和 $\mathrm{TiO}_{2}$ 的光催化特性, 制备了超亲/超 疏图案; Fujishima 等 ${ }^{[18]}$ 用阴极电沉积法制备 $\mathrm{ZnO}$ 纳 米柱, 并利用选择性区域光照获得超亲/超疏图案; Lin 课题组 ${ }^{[19-22]}$ 通过单分子自组装和光催化转印技 术, 在钛表面获得了超亲/超疏水阵列微图案.

本研究基于表面分子自组装和光催化转印技 术, 在 $\mathrm{TiO}_{2}$ 膜层表面获得超亲/超疏水阵列微图案 模板, 结合电化学沉积技术, 在 $\mathrm{TiO}_{2}$ 膜层表面构筑 钙磷盐膜层微图案, 并应用扫描电子显微镜(SEM) 和电子探针分析(EPMA) 对钻磷盐膜层微图案进行 分析和表征. 通过体外细胞培养实验, 考察钙磷盐膜 层微图案的生物性能, 探究成骨细胞在钙磷盐膜层 微图案上的粘附取向.

\section{1 实验部分}

\section{1 试 剂}

氢氟酸 $(\mathrm{HF})$ 、氟硅烷 $(\mathrm{PTES}) 、$ 硝酸钙 $\left(\mathrm{CaNO}_{3} \cdot\right.$ $\left.4 \mathrm{H}_{2} \mathrm{O}\right)$ 、磷酸二氢铵 $\left(\mathrm{NH}_{4} \mathrm{H}_{2} \mathrm{PO}_{4}\right)$ 、磷酸二氢钠 $\left(\mathrm{NaH}_{2} \mathrm{PO}_{4}\right.$. $\left.2 \mathrm{H}_{2} \mathrm{O}\right)$ 、磷酸氢二钠 $\left(\mathrm{Na}_{2} \mathrm{HPO}_{4} \cdot 12 \mathrm{H}_{2} \mathrm{O}\right)$ 为分析纯, 均购 于国药集团化学试剂有限公司. DMEM(Dulbecco's modified eagle medium)培养基、小牛血清、双抗伧存 液、肤酶消化液为生物试剂, 均购于鹭隆生物科技发 展有限公司.

\section{2 钻磷盐膜层微图案的电化学构筑与表征}

应用电化学阳极氧化 ${ }^{[23]}$ 的方法在纯钛表面构筑 一层 $\mathrm{TiO}_{2}$ 纳米管阵列膜, 然后将其在 $1 \%(w)$ 的 PTES-甲醇溶液中浸泡 $1 \mathrm{~h}$, 并于 $140{ }^{\circ} \mathrm{C}$ 烘烤 $1 \mathrm{~h}$, 获 得表面均匀的超疏水 $\mathrm{TiO}_{2}$ 纳米管阵列膜层. 将光掩
模贴覆在超疏水 $\mathrm{TiO}_{2}$ 纳米管表面, 紫外光照射 $1 \mathrm{~h}$, 得到形状和尺寸与光掩模一致的超亲/疏水图案 ${ }^{[19]}$. 将超亲/超疏水阵列模板浸人含 $0.042 \mathrm{~mol} \cdot \mathrm{L}^{-1}$ $\mathrm{Ca}\left(\mathrm{NO}_{3}\right)_{2}$ 和 $0.025 \mathrm{~mol} \cdot \mathrm{L}^{-1} \mathrm{NH}_{4} \mathrm{H}_{2} \mathrm{PO}_{4}$ 的电解液中, 在 $0.5 \mathrm{~mA} \cdot \mathrm{cm}^{-2}$ 的电流密度下电沉积一定时间 ${ }^{[24]}$, 获得钲磷盐膜层微图案. 应用日本 Hitachi 公司生产 的 S4800 扫描电子显微镜(SEM) 观察微图案膜层的 表面形貌. 用日本 Jeol 公司生产的 JXA-8100 电子 探针分析(EPMA)仪探测微图案表面的元素分布.

\section{3 体外细胞培养实验}

MG-63 细胞是一种成骨样细胞, 常被用来评价 仿生骨膜层的生物相容性. 本工作采用 MG-63 细胞 进行体外细胞培养实验. 将样品置于 24 孔培养板 中, 在孔中加人一定量的细胞悬液, 补充培养基, 培 养一定时间后取出, 经固定、脱水、冷冻干燥、喷金等 处理后, 用日本 Jeol 公司生产的 JSM6390 扫描电子 显微镜观测材料表面的细胞生长状态.

\section{2 结果与讨论}

\section{1 钻磷盐膜层微图案的表征}

电沉积制备钙磷盐膜层是通过控制电化学反 应, 调节阴极/溶液界面化学环境, 使电解液中的钲 磷物种在阴极表面相对高的 $\mathrm{pH}$ 环境下达到一定过 饱和, 进而从溶液相中结晶析出, 沉积在金属电极表 面. 图 1 为超亲/超疏水模板表面电沉积 $1 \mathrm{~min}$ 得到 的不同放大倍数下钻磷盐膜层微图案的 SEM 图. 从图中可以看出, 正方形的超亲水区域选择性地生 长了一层钻磷盐膜层, 而在修饰有氟硅烷的超疏水 区域则没有钙磷盐膜层. 这表明钙磷盐晶体只在超 亲/疏水图案模板特定的微单元区域选择性沉积, 从 而获得了纳-微米有序结构的钙磷盐生物材料微图 案. 䥻磷盐膜层只在超亲水区域沉积原因是: 将超 亲/超疏水阵列模板浸入溶液后, 超疏水区域的固/ 液界面会产成一层空气阻挡膜(Cassie model), 使得 电解液只能在超亲水区域铺展, 因而钙磷盐膜层仅 选择性地在超亲水区域沉积, 而不在超疏水区域沉 积.

图 $2(\mathrm{a}, \mathrm{b})$ 分别为钙磷盐膜层微图案中 $\mathrm{Ca} 、 \mathrm{P}$ 两 种元素的面扫描 EPMA 图. 右边的标尺中, 绿色和 蓝色代表元素浓度较高的区域, 黑色代表元素浓度 为零的区域. 由于钻磷盐选择性地优先在超亲水区 域内沉积, 导致 Ca、P 两种元素富集于正方形的超 亲水区域, 而超疏水区域的元素浓度则为零, 从而得 

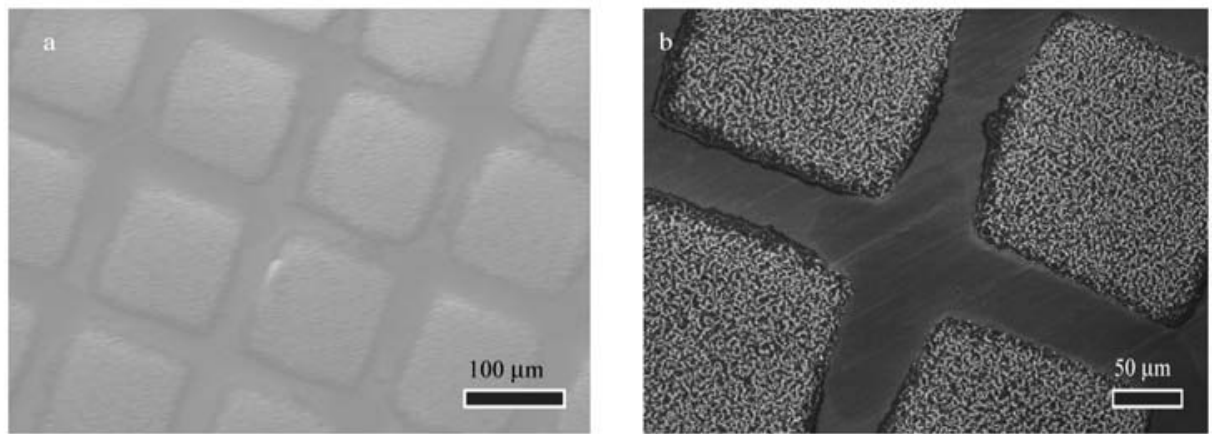

图 1 电化学沉积 $1 \mathrm{~min}$ 得到的钻磷盐膜层微图案不同放大倍数下的 SEM 图

Fig.1 SEM images of the patterned CaP films obtained by electrochemical deposition for 1 min with various magnifications
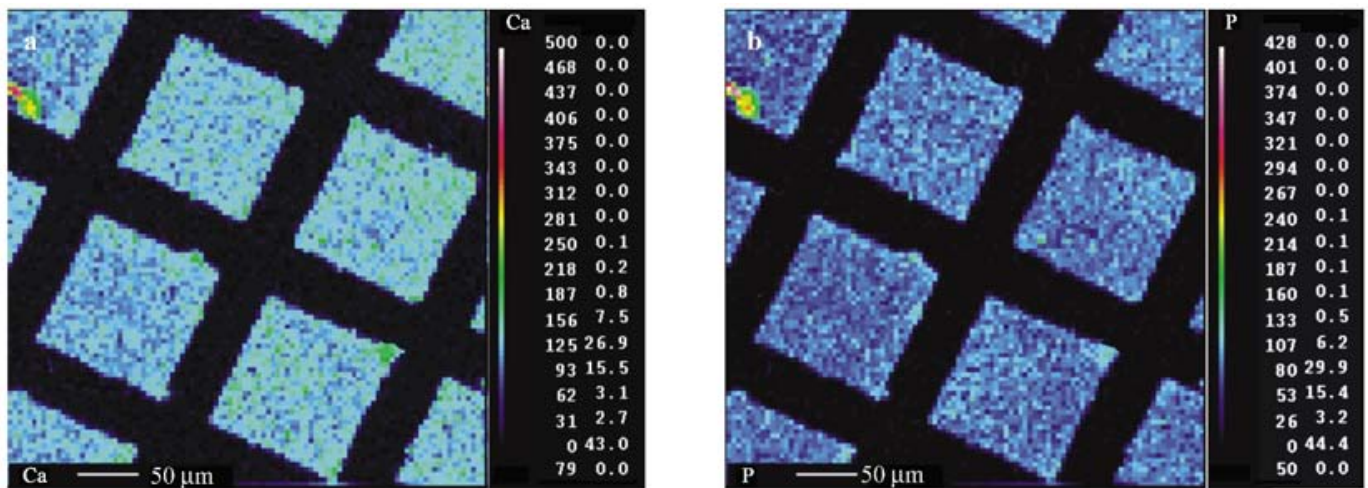

图 2 电化学沉积 $1 \mathrm{~min}$ 得到的钻磷盐膜层微图案的 EPMA 图

Fig.2 EPMA of the patterned CaP films by electrochemical deposition for $1 \mathrm{~min}$

(a) $\mathrm{Ca}$, (b) $\mathrm{P}$; The scale on the right side corresponds to element concentration which decreases from the top to bottom.

The first and second data list are signal intensity and area percentage of element, respectively.

到了与模板的形状和尺寸相一致的元素浓度分布 图, 这与 SEM 的结果是一致的.

\section{2 生物性能测试}

为了考察细胞在制得的钲磷盐膜层微图案上的 粘附取向, 采用体外细胞培养实验, 将 MG-63 成骨 细胞以 $1 \times 10^{-5} \mathrm{~cm}^{-2}$ 的密度种植于膜层表面, 孵化 6 $\mathrm{h}$ 后取出进行冷冻干燥处理, 用 SEM 观察成骨细胞 在图案表面的粘附状态. 图 3(a-c)分别为电沉积 1 、 3 和 $5 \mathrm{~min}$ 所得到的钙磷盐膜层微图案经体外细胞
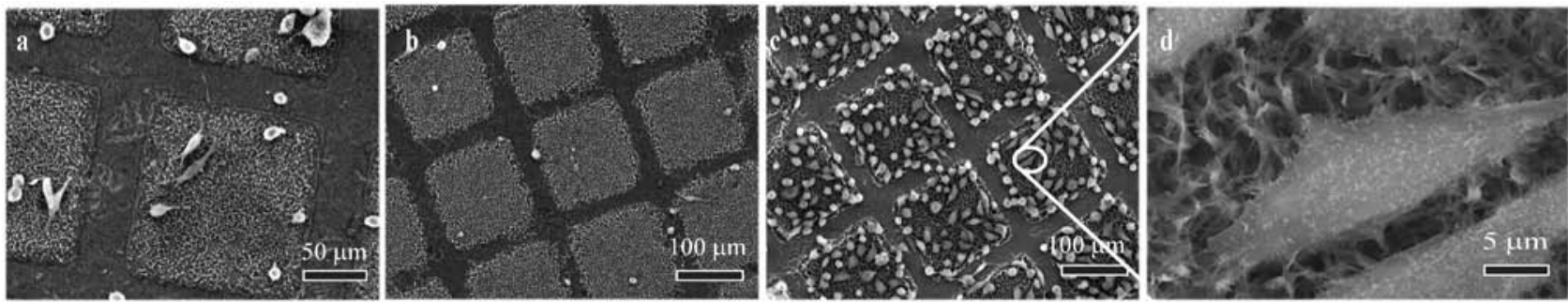

图 3 在不同电沉积时间的钻磷盐微图案表面培养 MG-63 细胞 $6 \mathrm{~h}$ 后的 SEM 图

Fig.3 SEM images of MG-63 cells cultured on the patterned CaP films for $6 \mathrm{~h}$ with different deposition time

deposition time: (a) 1 min, (b) 3 min, (c) 5 min; (d) higher magnification of (c) 
(图 3c)中细胞的粘附明显密集. 对细胞的粘附状态 的进一步观察发现, 在不同沉积时间所制得的微图 案膜层表面, 细胞的生长状态也有明显差异. 从图 $3 \mathrm{~d}$ 可以看出, 电沉积 $5 \mathrm{~min}$ 所得的样品表面细胞生 长的比较舒展, 可明显看到细胞的触须, 这表明随着 电沉积时间的延长, 钙磷盐膜层的致密性逐渐增加, 膜层的生物相容性提高, 细胞的粘附和生长状态 更好.

\section{3 结 论}

利用具有浸润性差异的阵列微图案模板, 结合 电化学沉积技术, 在 $\mathrm{TiO}_{2}$ 表面构筑了具有微-纳米 结构的钙磷盐膜层微图案. 分析表明, 超亲/疏水图 案模板能够诱导钙磷盐晶体在特定的区域选择性沉 积. 体外细胞培养实验表明, 细胞强烈地趋于在钙磷 盐膜层微单元中粘附, 且电沉积时间越长, 得到的钙 磷盐膜层越致密, 其生物相容性越好, 成骨细胞的生 长状态越好, 从而有望实现细胞定向生长的可控及 高通量评价细胞行为.

\section{References}

1 Discher, D. E.; Janmey, P.; Wang, Y. L. Science, 2005, 310: 1139

2 Whitesides, G. M.; Ostuni, E.; Takayama, S. Annu. Rev. Biomed Eng., 2001, 3: 335

3 Wan, Y. Q.; Wang, Y.; Liu, Z. M. Biomaterials, 2005, 26: 4453

4 Li, Y.; Yuan, B.; Ji, H. Angew. Chem. Int. Edit., 2007, 46: 1094

5 Sun, J. G.; Graeter, S. V.; Yu, L. Biomacromolecules, 2008, 9: 2569
6 Harrison, R. G. Anat. Rec., 1912, 6: 181

7 Dusseiller, M. R.; Schlaepfer, D.; Koch, M. Biomaterials, 2005, 26: 5917

8 Lussi, J. W.; Michel, R.; Reviakine, I. Prog. Surf. Sci., 2004, 76: 55

9 Schindler, M.; Ahmed, I.; Kamal, J. Biomaterials, 2005, 26: 5624

10 Hahn, M. S.; Miller, J. S.; West, J. L. Adv. Mater., 2006, 18: 2679

11 Miller, J. S.; Béthencourt, M. I.; Hahn, M. Biotechnol. Bioeng., 2006, 93: 1060

12 Lee, S. H.; Moon, J. J.; West, J. L. Biomaterials, 2008, 29: 2962

13 Teixeira, A. I.; Nealey, P. F.; Murphy, C. J. J. Biomed. Mater. Res. A, 2004, 71A: 369

14 Charest, J. L.; Eliason, M. T.; Garcia, A. J. Biomaterials, 2006, 27: 2487

15 Revzin, A.; Tompkins, R. G.; Toner, M. Langmuir, 2003, 19: 9855

16 Hui, E. E.; Bhatia, S. N. Langmuir, 2007, 23: 4103

17 Tadanaga, K.; Morinaga, J.; Matsuda, A.; Minam, T. Chem. Mater., 2000, 12: 590

18 Zhang, X. T.; Sato, O.; Fujishima, A. Langmuir, 2004, 20: 6065

19 Lai, Y. K.; Lin, C. J.; Wang, H.; Huang, J. Y.; Zhuang, H. F.; Sun, L. Electrochem. Commun., 2008, 10: 387

20 Lai, Y. K.; Huang, J. Y.; Gong, J. J.; Huang, Y. X.; Wang, C. L.; Chen, Z.; Lin, C. J. J. Electrochem. Soc., 2009, 156(11): D480

21 Lai, Y. K.; Lin, Z. Q.; Huang, J. Y.; Sun, L.; Chen, Z.; Lin, C. J. New J. Chem., 2010, 34(1): 44

22 Lai, Y. K.; Huang, Y. X.; Wang, H.; Huang, J. Y.; Chen, Z.; Lin, C. J. Colloids Surf. B, 2010, 76: 117

23 Lai, Y. K.; Sun, L.; Zuo, J.; Lin, C. J. Acta Phys. -Chim. Sin., 2004, 20: 1063 [赖跃坤, 孙 岗, 左 娟, 林昌健. 物理化学学报, 2004, 20: 1063]

24 Wang, H.; Lin, C. J.; Zhao, D. M.; Hu, R.; Zhang, F.; Lin, L. W. J. Biomed. Mater. Res. Part A, 2008, 87: 698 